\title{
Genetic divergence and genetic gain in bread wheat through selection practices
}

\author{
M. Ferdous, U. K. Nath and A. Islam \\ Department of Genetics and Plant Breeding, Bangladesh Agricultural University, Mymensingh \\ E-mail:m.ferdous122@yahoo.com
}

\begin{abstract}
Genetic diversity is essential to meet the diversified goals of plant breeding such as producing cultivars with increased yield, wider adaptation, desirable quality, pest and disease resistance. In this study genetic diversity and selection index of 24 genotypes of bread wheat were evaluated. The performance of 24 wheat genotypes showed that there were significant variations for the characters suggesting the presence of genetic variability among the genotypes. The genotypes were grouped into five clusters viz. I, II, III, IV and V based on Mahalanobis' ${ }^{2}$ statistics. Cluster I and II were the largest group containing six genotypes and the rest three clusters contained four, five and three genotypes respectively. The genotyps belonging to the same group had smaller $D^{2}$ - value than between those belonging to different clusters. Study on selection indices through discriminate function showed that Anza ranked as the best followed by the genotypes Rawal, PBW-373 and Kheri and suggests that these highest scoring genotypes might be recommended for farmers' cultivation for better yield and it would be expected genetic gain upto $49.77 \%$ through selection practices based on the characters studied. Therefore, a crossing programme could be made among the genotypes belonging in cluster I and cluster $V$ will provide maximum heterotic combination, especially for yield of bread wheat. Alternatively, among the studied genotypes Anza could be cultivated for better performance.
\end{abstract}

Keywords: Genetic divergence, Genetic gain, Selection indices, Bread wheat

\section{Introduction}

In Bangladesh wheat (Triticum aestivum) is the second important cereal crop next to rice and gaining popularity day-by-day. In terms of food value wheat is more nutritive than rice. It is the most widely adapted crop all over the world. About 2 million farmers of Bangladesh have benefited from wheat cultivation; about 600,000 people are employed for a period of 120 man-days during the wheat season, and 20 million tons of wheat has been produced in a period of last 20 years (Banglapedia, 2004). To feed the ever increasing population in the country, the need for more wheat will continue. There are many possibilities to increase wheat yields in Bangladesh through developing new high yielding varieties and by adoption of proper package of technology.

Genetic diversity is the basic for genetic improvement. It is widely accepted that information on germplasm diversity and genetic relatedness among elite breeding materials are fundamental elements in plant breeding (Mukhtar et al., 2002). Genetic diversity is very important factor for any hybridization program aiming at genetic improvement of yield especially in self pollinated crops (Joshi and Dhawan, 1966). Different methods have been used to assess genetic diversity. This can be obtained from pedigree analysis, morphological traits or using molecular markers. With the development of advanced biometrical method such as multivariate analysis based on Mahalanobis' (1936) $D^{2}$ statistics and Ward's non hierarchical squared Euclidean distance method have become popular to quantify magnitude of diversity among germplasm for their evaluation in respect of breeding program. For improving yield, selection index is also practiced on the basis of different yield contributing traits. Therefore, this piece of work has been performed to access genetic diversity and expecting higher genetic gain to improve yield in bread wheat.

\section{Materials and Methods}

Twenty four bread wheat genotypes viz Sonalika, Kalaynsona, Pavon, Ananda, Sawgat, Protiva, Sourab, Gourab, Satabdi, Sufi, Bijoy, Prodip, Kheri, Anza, Rawal, Raj-3765, HD-1553, GW-322, PBW-373, CB-38, CB-43, CB-50, CB-51 and CB-53 were selected for this study. The experiment was carried out at the experimental farm, Department of Genetics and Plant Breeding, Bangladesh Agricultural University, 
Mymensingh during the period from November 2008 to March 2009. The experiment was set up in randomized complete block design (RCBD) with three replications. Five plants from each plot were randomly selected to collect the thirteen important characters such as days to booting, days to heading, days to anthesis, leaf area index, flag leaf area duration, days to physiological maturity, plant height, no. of effective tillers plant ${ }^{-1}$, spikelets spike ${ }^{-1}$, grains spike ${ }^{-1}, 100$ grain weight, yield plant $^{-1}$ and harvest index, Analysis of variance was performed using the plant breeding statistical program (PLABSTAT, Version 2N, Utz, 2007) with the following model:

$$
Y_{i j}=g_{i}+r_{j}+\varepsilon_{i j}
$$

Where, $Y_{i j}$ was observation of genotype i in replicates $j, g_{i}$ and $r_{j}$ were effects of genotype $i$ and replicates $\mathrm{j}$, respectively and $\varepsilon_{\mathrm{ij}}$ was the residual error of genotype $\mathrm{i}$ in replicate $\mathrm{j}$. The replicates were considered as random factors. Multiple mean comparisons were made with Fisher's least significant difference (LSD) procedure using StatGraphics Plus for Windows 3.0 (Statistical Graphics Crop. Rockville, USA).

Calculation of $D^{2}$ Values: The Mahalanobis' distance $\left(D^{2}\right)$ values were calculated from transformed uncorrelated means of characters according to Rao (1952) and Singh and Chaudhury (1985). For each combination the mean deviation, i.e $Y^{1}{ }_{i}-Y^{2}{ }_{i}$ with $i=1,2, \ldots \ldots \ldots \ldots . p$ genotypes were estimated and the $D^{2}$ was calculated as sum of the squares of these deviations, i.e $\Sigma\left(Y_{i}^{1}-Y_{i}^{2}\right)^{2}$. The $D^{2}$ values were estimated for all possible pairs of combinations between genotypes.

Clustering: The $D^{2}$ values of genotypes were arranged in order of relative distances from each other by the method suggested by Tocher (Rao 1952) and Singh and Chaudhary (1985) was used for cluster formation. Selection indices were constructed using the methods developed by Smith (1936) based on the discriminate function of Fisher (1936).

\section{Result and Discussion}

The genotypes were significantly different from each other for grain yield and different yield contributing characters. Using Mahalanobis' $D^{2}$ statistics and Tocher's method, the genotypes were grouped into five clusters (Table 1). Cluster I and II had same no. of genotypes i.e six and they were the largest cluster. The cluster IV was in second position with 5 genotypes. The cluster III and V contained 4 and 3 genotypes respectively.

Table 1. Clustering pattern of 24 genotypes of wheat based on Mahalanobis' $D^{2}$-values and the member present in each respective cluster

\begin{tabular}{|c|c|c|l|}
\hline $\begin{array}{c}\text { Cluster } \\
\text { number }\end{array}$ & $\begin{array}{c}\text { Number of } \\
\text { genotypes }\end{array}$ & Percent & \multicolumn{1}{|c|}{ Name of genotypes } \\
\hline I & 6 & 25 & $\begin{array}{l}\text { Satabdi, Bijoy, Kalayansona, GW-322, CB-51, } \\
\text { Sonalika }\end{array}$ \\
\hline II & 6 & 25 & Sufi, pavon, CB-53, CB-38, CB-43, Ananda \\
\hline III & 4 & 16.67 & Prodip, Sourav, Protiva, Gourav \\
\hline IV & 5 & 20.83 & CB-50, PBW-373, Kheri, Rawal, Anza \\
\hline V & 3 & 12.5 & Raj-3765, HD-1553, Sawgat \\
\hline
\end{tabular}

Dendrogram indicated grouping of 24 genotypes of wheat into five clusters (Fig. 1). Satabdi, Bijoy, Kalayansona, GW-322, CB-51 and Sonalika grouped in cluster I with high genetic (7.54) distance; Sufi, pavon, CB-53, CB-38, CB-43 and Ananda in cluster II which had highest genetic distance (8.17; while Prodip, Sourab, Protiva and Gourab on cluster III with 6.68 and CB-50, PBW-373, Kheri, Rawal, Anza on cluster IV with 6.35 which was lowest genetic distance. Finaly Raj-3765, HD-1553, Sawgat on cluster V. 


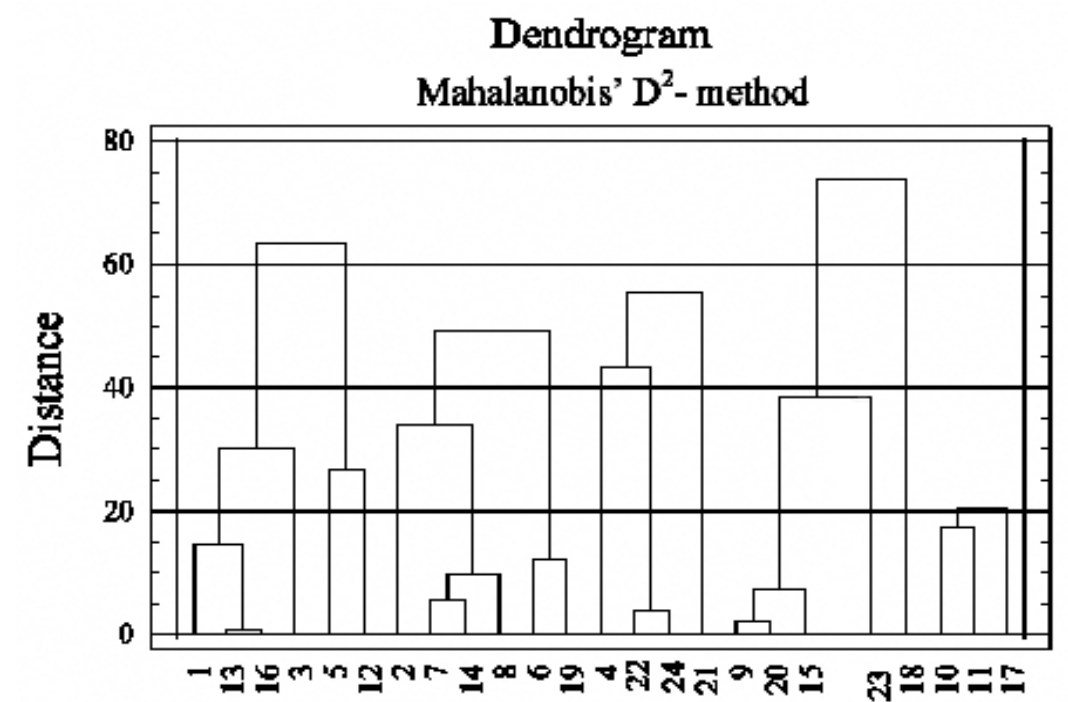

\begin{tabular}{|l|l|l|l|}
\hline $1=$ Satabdi & $8=$ CB-38 & $14=$ CB -43 & $20=$ Rawal \\
$2=$ Sufi & $9=$ CB-50 & $15=$ PBW 373 & $21=$ Sourab \\
$3=$ Bijoy & $10=$ Raj 3765 & $16=$ Sonalika & $22=$ Protiva \\
$4=$ Prodip & $11=$ HD 1553 & $17=$ Sawght & $23=$ Anza \\
$5=$ Kalayansona & $12=$ GW 322 & $19=$ Kheri & $24=$ Gourab \\
$6=$ Pavon & $13=$ CB-51 & & \\
$7=$ CB-53 & & & \\
\hline
\end{tabular}

Fig. 1. Dendrogram based on genetic distance, summarizing the data on differentiation between 24 wheat genotypes according to Mahalanobis' $D^{2}$ method

Elias and Shamsuddin (2000) carried out an experiment with 16 genotypes of bread wheat for study the genetic divergence with the help of Mahalanobis $D^{2}$-statistics. They constructed six distinct clusters form those genotypes and reported that grain yield per square meter contributed maximum to the total divergence. This was followed by 1000-grain weight, number of grains per spike and grain filling period, whereas vegetative period contributed the least. Ribadia et al., (2007) also studied the genetic divergence among 50 exotic genotypes of wheat by employing Mahalanobis's $D^{2}$ analysis based on 10 characters. The genotypes were grouped into six clusters. Cluster I was the largest with 38 genotypes followed by clusters II and III containing 7 and 2 genotypes, respectively. The highest inter-cluster distance was observed between cluster II and $\mathrm{V}$ followed by that between cluster I and V, suggesting more variability in genetic makeup of the genotypes included in these clusters. Cluster II had the highest mean values for grain yield plot $^{-1}$

Selection index was constructed to identify suitable genotypes among 24 varieties of wheat considering eight characters viz. days to heading, days to anthesis, days to physiological maturity, no. of effective tillers plant ${ }^{-1}$, grain spike ${ }^{-1}, 100$ grain weight, harvest index and grain yield (Table 2). Genotype Anza achieved the highest selection score (331.81) and ranked as the best followed by the genotypes Rawal, PBW-373 and Kheri with $323.27,322.54$ and 320.10 respectively. The genotype Raj-3765 was worst having the lowest selection score of 241.38 followed by HD-1553 (254.39) and CB-53 (264.92). The expected genetic gain $(\Delta G)$ was 49.77 at $5 \%$ selection intensity i.e 2-3 highest scoring genotypes from these 24 wheat genotypes might be recommended for farmers' cultivation for better yield.

Uddin el al., (1997) stated a selection index revealed that three variable indices including grain yield plant $^{-1}$, spikes plant ${ }^{-1}$, and 1000-grain weight gave the highest relative efficiency over straight selection for grain yield plant ${ }^{-1}$ in spring wheat. Siahoosh et al., (2001) conducted an experiment during 1997-98 in two locations in Iran to evaluate selection indices for increasing grain yield in 25 wheat cultivars and they showed that grain yield, number of grains spike ${ }^{-1}$ and number of spikelets spike ${ }^{-1}$ were the best indices for increasing grain yield in wheat. 
It could be concluded from the present study that a crossing programme could be made among the genotypes belonging in cluster I and cluster $V$ for getting maximum heterotic combinations, especially for yield of bread wheat. Alternatively, among the studied genotypes Anza could be cultivated for better performance and also it could be suggested that there is possibility to achieve nearly $50 \%$ genetic advance through selection practices among the cultivated varieties.

Table 2. Selection score, rank and expected genetic gain of 24 genotypes of Wheat considering eight characters

\begin{tabular}{|c|c|c|c|}
\hline SL No & Genotypes & Selection score & Rank \\
\hline 1 & Satabdi & 305.28 & 8 \\
\hline 2 & Sufi & 279.70 & 19 \\
\hline 3 & Bijoy & 280.50 & 17 \\
\hline 4 & Prodip & 292.09 & 13 \\
\hline 5 & Kalayansona & 310.72 & 6 \\
\hline 6 & Pavon & 287.96 & 15 \\
\hline 7 & CB-53 & 264.92 & 22 \\
\hline 8 & CB-38 & 279.37 & 20 \\
\hline 9 & CB-50 & 313.01 & 5 \\
\hline 10 & Raj-3765 & 241.38 & 24 \\
\hline 11 & HD-1553 & 254.39 & 23 \\
\hline 12 & GW-322 & 309.97 & 7 \\
\hline 13 & CB-51 & 304.01 & 9 \\
\hline 14 & CB-43 & 280.15 & 18 \\
\hline 15 & PBW-373 & 322.54 & 3 \\
\hline 16 & Sonalika & 293.09 & 11 \\
\hline 17 & Sawgat & 275.40 & 21 \\
\hline 28 & Kheri & 320.10 & 4 \\
\hline 19 & Ananda & 300.50 & 10 \\
\hline 20 & Rawal & 323.27 & 2 \\
\hline 21 & Sourab & 288.45 & 14 \\
\hline 22 & Protiva & 292.78 & 12 \\
\hline 23 & Anza & 331.81 & 1 \\
\hline 24 & Gourab & 280.75 & 16 \\
\hline
\end{tabular}

\section{References}

Banglapedia. 2004. National Encyclopedia of Bangladesh. Asiatic Society of Bangladesh. 3:141-142.

Elias, M.A. and Shamsuddin, A.K.M. 2000. Genetic divergence in bread wheat (Triticum aestivum L.) for source sink characters. Bangladesh Journal of Genetics and Plant Breeding. 13(2):19-24.

Fisher, R.A. 1936. The use of multiple measurements in taxonomic problems. Ann. Euge. 7: 179-188.

Joshi, A.B. and Dhawan, N.L. 1966. Genetic improvement of yield with special reference to self fertilizing crop. Indian Journal of Genetics and Plant Breeding. 26A:101-113.

Mahalanobis, P.C. 1936. On the generalized distance in Statistics. Proc. Nat. Inst. Sci. Ind. 2:49-55.

Mukhtar, M.S., Rahman, M. and Zafar, Y. 2002. Assessment of genetic diversity among wheat (Triticum aestivum L.) cultivars from a range of localities across Pakistan using random amplified polymorphic DNA (RAPD) analysis. Euphytica. 128: 417-425.

Rao, C.R. 1952. Advanced statistical method in biometrical research. John Willey and Sons, New York.

Ribadia, K.H., Dobariya, K.L., Ponkia, H.P. and Jivani, L.L. 2007. Genetic diversity in macaroni wheat (Triticum durum Desf.). J. Maharashtra Agril. Univ. 32(1):32-34.

Siahoosh, M.R., Asad, M.T., Emam, Y., Saidi, A. and Kherradnam, M. 2001. Implication of four selection indices in wheat cultivars (Triticum aestvum L.) for increasing the grain yield. Iranian J. Agril. Sci. 32(1):219-236.

Singh, R.K. and Chaudhary, B.D. 1985. Biometrical methods in quantitative genetic analysis. Kalyani Publishers, New Delhi. $225-252$.

Smith, H.F. 1936. A discriminant function for plant selection. Ann. Eugn. 7:240-250.

Uddin, M.J., Biswanath, M. and Chowdhury, M.A.Z. 1997. Genetic paraments, correlation, path coefficient analysis and selection indices in wheat, Bangladesh J. Sci. Ind. Res. 32(4):523-528.

Utz, H.F. 2007. PLABSTAT (Version 2N). A computer program for the computation of variances and covariances. Institute of Plant Breeding, Seed Science and Population Genetics, University of Hohenheim, Stuttgart, Germany. 